\title{
Perspective of Caesarean section delivery and its health risks on children among Indonesian pediatricians
}

Received $25^{\text {th }}$ August 2020, Accepted $15^{\text {th }}$ September 2020

Link to DOI:

10.25220/WNJ.V04.S2.0008

Journal Website:

www.worldnutrijournal.org

\author{
Ray Wagiu Basrowi ${ }^{1 *}$, Tonny Sundjaya ${ }^{1}$, Nova Lidia Sitorus ${ }^{1}$, Bertri Maulidya Masita ${ }^{1}$
}

1. Danone SN Indonesia

\begin{abstract}
An increasing trend of C-section delivery In Indonesia was found from 2\% in 1986 to 16\% in 2012. This delivery method was introduced to save women and their newborn baby's life. On the other side, it can increase short and long-term health risks for children. This study aims to assess and give an overview of the perspective on pediatrician as medical specialist in managing children of the Csection delivery history. A survey was conducted on 89 Indonesian Pediatricians using an online questionnaire. It was found that most pediatrician chose combination partial hydrolyze milk combined with synbiotic (a combination of prebiotic and probiotic) combination as nutrition intervention to decrease the allergy risk on children with C-section delivery mode, and there is a need to emphasize information about short and long-term health effects of C-section, especially in causing gut dysbiosis and its mechanism, information on non-medical causes of gut dysbiosis to increase awareness of recommending right symbiotic to decrease allergy risk in children with Csection history.
\end{abstract}

Keywords: C-section, allergy, synbiotic, infants, pediatrician

\section{Introduction}

Caesarian Section, or often called as C-section delivery mode was introduced to save women and their newborn baby's life and become a major obstetric intervention in the late nineteenth century, from life-threatening pregnancy and child-birth related complications. ${ }^{1}$ In $\mathrm{C}$-section delivery mode, infant is not in contact with maternal vaginal and enteric contents. ${ }^{2}$ According to the World Health Organization (WHO), a global incremental percentage of C-section about $10-15 \%$ in both developed and developing countries since $1985 .{ }^{3}$ In

\section{Corresponding author:}

Dr. dr. Ray Wagiu Basrowi, MKK

Science and Medical Affairs Department

Danone SN Indonesia

Email: ray.basrowi1@danone.com
Indonesia, an increasing trend from $2 \%$ in 1986 to 16\% in 2012 was found. ${ }^{4}$ From Indonesia's Basic Health Research (Riset Kesehatan Dasar/Riskesdas), C-section was found to be increasing from $9.8 \%$ in 2013 to $17.6 \%$ in 2018 from all childbirths. ${ }^{5,6}$

Despite the fact that the aim of C-section delivery mode is to save lives and reducing the maternal and neonatal mortality rate from lifethreatening pregnancy and child-birth, it has health risks that can be seen directly (short term health risks) and long term health consequences on children health. ${ }^{7}$ Short term health risks include altered immune development, ${ }^{7-9}$ reduced intestinal gut microbiome, ${ }^{7,9,10}$ and increased likelihood of allergy and asthma. ${ }^{7,11}$ For the long term, it was founded that C-Section to be associated with a greater possibility of late childhood obesity ${ }^{7,11}$ and possibly influence child cognitive development. ${ }^{7,12}$ 
Ideally, C-section should be performed when medically necessary.

The colonization of gut microbiota has an important role in the development of immune system in infants' early life, ${ }^{8,9,13}$ some of the microbiota colonization associated with allergy that linked to infection so both may share protective environment interaction. ${ }^{13,14}$ However, the initial gut microbiota of infants born by $\mathrm{C}$-section differed from a vaginal delivery. ${ }^{10,13} \mathrm{C}$-section delivery may cause a dysbiosis of the gut microbiota which challenges the normal development of an immune system and can be associated with an increased risk of developing an allergy.., 14

The consequences of C-section delivery mode might have an impact on the First 1,000 Days of life. ${ }^{15}$ Good nutrition during pregnancy and early childhood plays a foundational role in enabling a child to grow, develop and reduce disease risk. ${ }^{16,17}$

This survey aimed to explore the perspective of pediatricians as a medical specialist in managing children born via $\mathrm{C}$-section that related to the $\mathrm{C}$ Section delivery mode and its health risks on children.

\section{Methods}

An online survey was conducted to 89 pediatricians from March to April 2020, using Google-form survey platform and distributed through email and followed up with direct interview. Respondents were recruited from Danone HCPs (Health Care Practitioners) database and obtain informed consent regarding the purpose and ethical consideration of the study.

The questionnaire consists of 12 multiple choice questions, divided to 4 demographic questions and 8 questions related to C-section delivery history and its health risks on children. Knowledge and attitude were also explored. ${ }^{18,19}$ This questionnaire was adapted and referred to previous study, and addressing 5 topics such as $\mathrm{C}$-section impact on children, gut dysbiosis cause, gut dysbiosis effect, the importance of 1000 days of life, synbiotic effect. ${ }^{7,10,14}$ The data presented in descriptive report.

\section{Results}

All of the 89 respondents participated in this survey were pediatricians, $43 \%$ of them had less than 5 years of service and majority (63\%) worked in government affiliated hospital. Most of the respondents (93\%) reported that they have consulted on children with C-Section delivery history in the last 3 months, and mostly (65\%) received C-section patient consultation for more than 10 patients. The demographic characteristics of the respondents can be seen in Table 1.

The understanding of respondent on the impact of C-section toward future health of babies varies from altered immune system (56\%) and potential risk of gut dysbiosis (43\%) (Figure 1). In Figure 2, most of respondents $(77 \%)$ understand that babies born with C-section will potentially have bigger risk of allergy in later life. However, as shown in Figure 3 , on the further question related to the other cause of gut dysbiosis apart of C-section, respondents aware that antibiotic usage $(55 \%)$, pollution exposure (35\%) and obesity $(10 \%)$ were also potential causative factors.

Table 2 shows that majority of respondents (91\%) were aware on an increased risk of allergy due to gut dysbiosis, as they were also aware that both allergy risk and gut dysbiosis could potentially caused by C-Section delivery method (82\%). Specifically on the nutrition intervention, $71 \%$ of respondents agree to recommend the partial hydrolyzed formula with synbiotic could potentially decrease risk of allergy among infants born with Csection and not exclusively breastfed.

\section{Discussion}

Studies showed that the increased rate of Caesarean section delivery in the last decades potentially contributed to the rising allergy epidemic.,11 Finding of our survey showed that the pediatricians in Indonesia also understand this potential risk and even aware the underlying mechanism which was include the potential gut dysbiosis in digestive system and its link to the immune system development. Recent studies showed that C-section is associated with delayed colonization gut microbial which is aberrant short-term immune responses to the newborn infant, which was also a 
greater risk of developing an immune disease such as asthma, allergies, laryngitis and gastroenteritis. ${ }^{7,9,10}$ Children born by Caesarean delivery had a higher possibility in developing food allergy compared with children who were born vaginally. ${ }^{9}$

Study revealed that a baby born vaginally have produced more cytokines implicated in neonatal immunity also their intestinal microbiota plays a role in the development of immune system in early life. ${ }^{10}$ However, it is still unknown whether C-section causes a long-term effect on the immune system of the offspring that contributes to compromised future immune health. ${ }^{8}$ Therefore, it is prudent to understand the consequences of $\mathrm{C}$-section for children among pediatricians to reduce the burden of pediatricians in its diagnosis and treatment.

Theoretically, the first initial gut microbiota was transferred from mother to infant through the birth channel, ideally via vaginal. ${ }^{10,13}$ The early establishment of gut microbiota is required to develop the immune system of newborn infant. ${ }^{13,14}$ However, the initial gut microbiota of infants delivered by $\mathrm{C}$-section differed from vaginally delivered infants and resemble the skin microbiota (such as Staphylococcus, Acinetobacter) rather than the mothers' vaginal microbiota (Lactobacillus). ${ }^{9,10}$ Differences in the delivery mode in terms of gut microbiota colonization may explain the higher risks of allergy in infants born by $\mathrm{C}$-section as compare to born vaginally because they had a different composition of protective bacteria. ${ }^{13,14}$ Moreover, infants born by $\mathrm{C}$-section also lacked of the early initiation of breast milk or colostrum which supposed to be the best source of gut micro biota development factors. ${ }^{8,9,10,13}$

Our study found that the respondents recognized antibiotic use, pollution exposure and obesity can cause gut dysbiosis. Previous research has suggested that antibiotic usage in early life was associated with the development childhood allergy and asthma, moreover, from cohort study reported that $65 \%$ children had received at least one antibiotic prescription during the first year of life ${ }^{20}$. Antibiotic can disturb the gut microbiota, possibly perturbing the developing immune system. It impacts on early immune developing that will increase the risk of immunologic problem like an allergy. ${ }^{8,9,21}$ There are number studies examined the antibiotic exposure increased the risk of pediatric atopic or asthma. ${ }^{9,21}$ Current medical care promotes the use of antibiotics have to change the pattern of infectious disease and bacterial exposure in infancy that the use of antibiotics should be reduced.

Currently, there is growing evidence that air pollution (i.e. smoke) is a risk of the factor of development allergy or asthma symptoms in children. ${ }^{9,22}$ A study reported that maternal who exposure to air pollutant during pregnancy, is associated with an increased risk of allergic disease. The results stated that childhood allergic diseases are triggered by air pollution in third trimesters pregnancy, it might the transmission of maternal microbiota has impeded. ${ }^{22}$ The link of obesity and gut dysbiosis have shown that breast milk from obese mothers contains differed various microbial than normal-weight mothers. ${ }^{9}$

Understanding the effects of gut dysbiosis among infants born by $\mathrm{C}$-section is key for potential nutrition intervention, including supplementation prebiotic, probiotic or synbiotic formula. ${ }^{8,13}$ Most respondents recognized that the use of synbiotic can reduce the allergy risks in children with $\mathrm{C}$-section history, they also acknowledged the importance of proper nutrition intervention on the first thousand days of life among children with $\mathrm{C}$-section history to prevent fatal allergy. A previous study proved that the formula supplemented with synbiotic (scGos/lcFos and Bifidobacterium breve M16-V) has opportunities to modulate the gut health and reduce severity of atopic dermatitis in infants born via Csection $^{14}$. Also another study confirmed the synbiotic can reduce atopic dermatitis severity and reduce the symptom of asthma in 1 year follow-up the infants ${ }^{23}$.

Given the uncertainty of predicting risk for allergy in the early life of children, prevention is of utmost importance. Pediatrician in this study agreed to recommend the partial hydrolyzed milk that combined with synbiotic to decrease allergy risk for infants born via $\mathrm{C}$-section who were not breastfed. The combination of prebiotic and probiotic is able to compensate for the infants to restore the delayed Bifidobacterium colonization. Previous studies indicate that some allergies can be obviated by using synbiotic. ${ }^{13,23,24}$ The aspect of cost-effectiveness and health economics review should also need to be taken into account when it comes to nutrition 
intervention. $^{25,26}$ Therefore the perspective of respondents of this study toward synbiotic with the partial hydrolyzed milk to infants born via $\mathrm{C}$-section is evidence-based and rational with existing studies.

Nevertheless, we identify that the limited numbers of respondents, which was less than 100 participants, was the major limitation of this study. The subjectivity of respondents may as well interfere the objectivity of the study through online survey-based. The knowledge competency as well as updated education program should also need to be considered in future research, as study showed that retaining medical staff's knowledge and quality of care through training on specific skills is strongly needed and potentially influence the skill and competency. ${ }^{27,28}$ It is important to conduct better structured survey with bigger sample size to identify the in-depth perspective, understanding and knowledge of Indonesian pediatricians toward Csection and its impact to long-term health.

\section{Conclusion}

Overall, the knowledge and understanding of pediatricians toward $\mathrm{C}$-section methods and its impact on long-term health of children were mainly recognizing the aspect of increased risk of allergy and potential gut dysbiosis. Although other factors such as antibiotic use and pollution should also be considered. Given the recent increase in C-section cases and the threat posed by gut dysbiosis and allergy-induced in infants, it is essential that better intervention made in the provision of care for infants born via $\mathrm{C}$-section. Opportunities for improvement available as acknowledge by the pediatrician in using combination partial hydrolyzed milk combined with synbiotic as a nutrition intervention to decrease the allergy risk on children with $\mathrm{C}$ Section delivery mode who were not breastfed.

Table 1. Demographic characteristic of respondents

\begin{tabular}{|c|c|c|}
\hline \multirow[t]{2}{*}{ Variables } & \multicolumn{2}{|c|}{ Pediatricians } \\
\hline & $\mathrm{n}$ & $\%$ \\
\hline \multicolumn{3}{|l|}{ Length of services } \\
\hline$<5$ years & 38 & 43 \\
\hline $5-10$ years & 22 & 25 \\
\hline $10-15$ years & 12 & 13 \\
\hline$>15$ years & 17 & 19 \\
\hline \multicolumn{3}{|l|}{ Affiliation } \\
\hline Private hospital & 56 & 63 \\
\hline Government hospital & 33 & 37 \\
\hline \multicolumn{3}{|c|}{ Ever consulted children with C-Section history in the last 3 months } \\
\hline Yes & 86 & 97 \\
\hline No & 3 & 3 \\
\hline \multicolumn{3}{|c|}{ Number of children with C-section history consulted per months } \\
\hline$<10$ patients/ month & 31 & 35 \\
\hline$>10$ patients/month & 58 & 65 \\
\hline
\end{tabular}

Table 2. Knowledge and attitude of children's health risk and C-section delivery history

\begin{tabular}{lcc}
\hline \multicolumn{1}{c}{ Variables } & Pediatricians \\
\cline { 2 - 3 } & $\mathrm{n}$ & \% \\
\hline Knowledge on increase of allergy risk in children due to Gut dysbiosis & 91 \\
Yes & 6 & 7 \\
No & 2 & 2 \\
Don't know & & \\
Knowledge of allergy risk and gut dysbiosis caused by children with & & \\
C-section delivery history & 73 & 17 \\
Yes & 15 & 1 \\
No & 1 & 1 \\
Don't know & \\
\hline
\end{tabular}


Table 2. Knowledge and attitude of children's health risk and C-section delivery history (continued)

\begin{tabular}{lcc}
\multicolumn{1}{c}{ Variables } & Pediatricians \\
\cline { 2 - 3 } & $\mathrm{n}$ & $\%$ \\
\hline Importance of nutrition on first 1000 days and allergy risk in children & 87 & 98 \\
Yes & 1 & 1 \\
No & 1 & 1 \\
Don't know & & \\
C-Section baby without breastfeed and usage of partial hydrolyzed & & 71 \\
milk combined with synbiotic to decrease allergy risk in children & 63 & 16 \\
Yes & 14 & 11 \\
No & 10 & 2 \\
Doubt/ uncertain & 2 & \\
Don't know & & \\
\hline
\end{tabular}

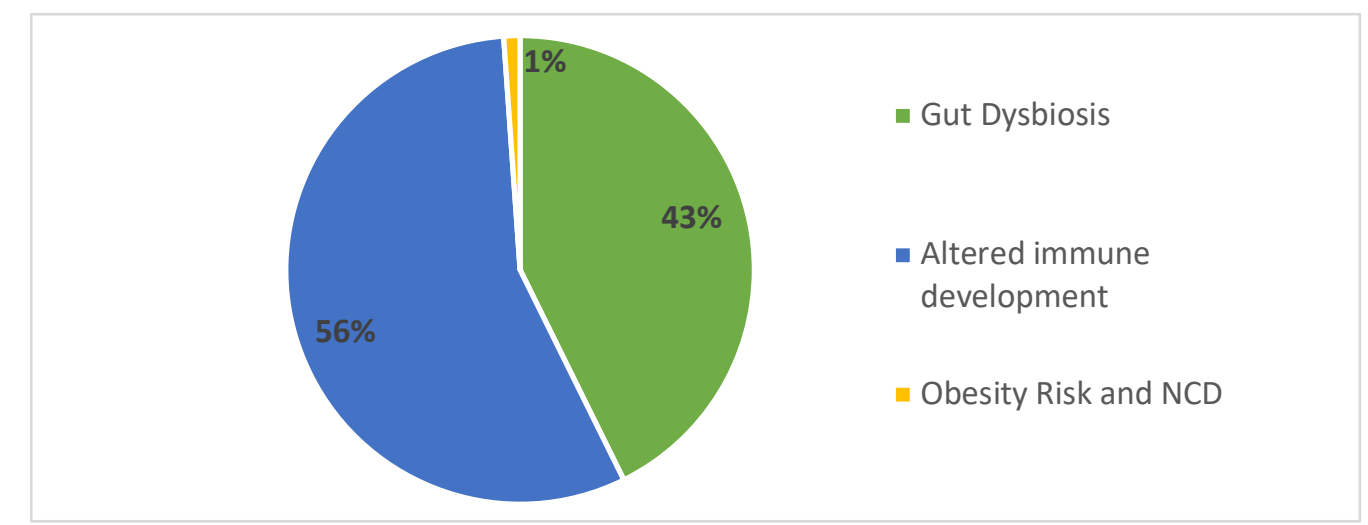

Figure 1. Knowledge of health risk of children with C-section history

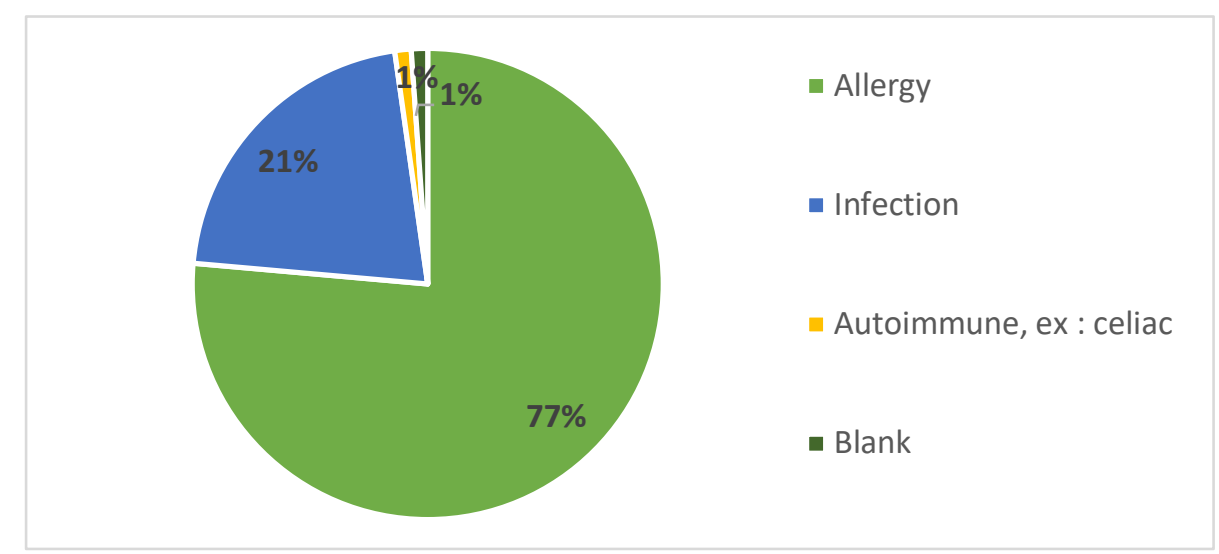

Figure 2. Knowledge on impact of children with C-section history to digestive and immune systems 


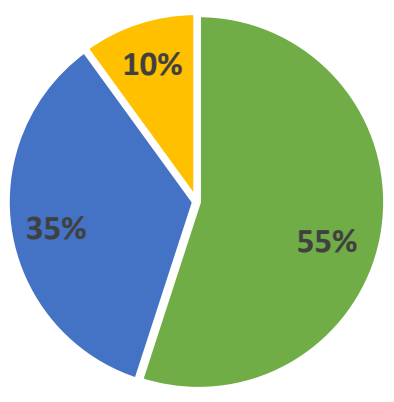

- Antibiotic usage

- Pollution exposure, ex : smoke

- Obesity

Figure 3. Knowledge on other causes of gut dysbiosis other than C-Section

\section{Conflict of Interest}

This study was funded by Danone SN Indonesia.

\section{Open Access}

This article is distributed under the terms of the Creative Commons Attribution 4.0 International Licence (http://creativecommons.org/licenses/by/4.0/), which permits unrestricted use, distribution, and reproduction in any medium, provided you give appropriate credit to the original author(s) and the source, provide a link to the Creative Commons license, and indicate if changes were made.

\section{Reference}

1. Teguete I, Dolo A,Sissoko A, Thera A, Traore M, Djire $M$, et al. Determining Factors of Cesarean Delivery Trends in Developing Countries : Lessons from Point G National Hospital (BamakoMali).INTECH Open Access Publisher; 2012

2. Rutayisire E, Huang K, Liu Y, Tao F. The mode of delivery affects the diversity and colonization pattern of the gut microbiota during the first year of infants' life: a systematic review. BMC Gastroenterology 2016; 16: 86.

3. World Health Organization, HRP. WHO Statement on Caesarean Section Rates. Geneva; 2015.
4. Nababan HY, Hasan M, Marthias T, Dhital R, Rahman A, Anwar I. Trends and inequities in use of maternal health care services in Indonesia, 19862012. Int J Womens Health. 2017;10:11-24.

5. Agency of Health Research and Development (Indonesia). Basic Health Research; 2013.

6. Agency of Health Research and Development (Indonesia). Basic Health Research; 2018.

7. Sandall J, Tribe R, Avery L, Mola G, Visser G, Homer C,et al. Short-term and long-term effects of caesarean section on the health of women and children. The Lancet 2018; 392(10155), pp.13491357.

8. Kristensen, K. and Henriksen, L. Cesarean section and disease associated with immune function. Journal of Allergy and Clinical Immunology 2016; 137(2), pp.587-590.

9. Martin R, Nauta A, Ben Amor K, Knippels L, Knol $\mathrm{J}$, Garssen J. Early life: gut microbiota and immune development in infancy. Beneficial Microbes 2010 ; 1(4), pp.367-382.

10. Salas Garcia M, Yee A, Gilbert J, Dsouza M. Dysbiosis in Children Born by Caesarean Section. Annals of Nutrition and Metabolism 2018; 73(3), pp.24-32.

11. Neu, J. and Rushing, J. Cesarean Versus Vaginal Delivery: Long-term Infant Outcomes and the Hygiene Hypothesis. Clinics in Perinatology 2011; 38(2), pp.321-331.

12. Polidano, C., Zhu, A. and Bornstein, J. The relation between cesarean birth and child cognitive development. Scientific Reports 2017; 7(1) 
13. Angela M-P, Pauline L, Ingrid B. Renes, Shugui W, Yuliya $\mathrm{B}$, et al. Intervention strategies for cesarean section-induced alterations in the microbiota-gutbrain axis. Nutrition Reviews 2017; 75(4): 225-240.

14. Rch.org.au. 2020. [online] Available at: $<$ https://www.rch.org.au/uploadedFiles/Main/Conte nt/ccchdev/CCCH-The-First-Thousand-Days-AnEvidence-Paper-September-2017.pdf $>$ [Accessed 17 May 2020].

15. Thousanddays.org. 2020. [online] Available at: $<$ https://thousanddays.org/wpcontent/uploads/1000Days-Nutrition_Brief_BrainThink_Babies_FINAL.pdf $>$ [Accessed $\overline{17}$ May 2020].

16. Kabaran, S. Maternal and Child Nutrition: Importance of the First 1000 Days. International Journal of Clinical Nutrition \& Dietetics 2018; 4(2).

17. Chua Mei C, Ben A, K, Lay C, Goh Anne E.N, Chiang W C, Rao R, et al. Effect of synbiotic on the gut microbiota of cesarean delivered infants a randomized, double-blind, multicenter study. Journal of Pediatric Gastroenterology and Nutrition 2017; Volume 65, p102-106

18. Basrowi RW, Krisnamurti D, Wibowo Y, Vandenplas Y (2019) Factors influencing probiotics recommendation among pediatricians in Indonesia. IFNM. 2019; 6:1-4. doi: 10.15761/IFNM.1000265

19. Basrowi RW, Wasito E, Sundjaja T. Perspective of Soy Formula and Fiber Intake among Non-Cow's Milk Drinker Pediatric Patients: A Survey among Indonesian Health Care Practitioners. World Nut J 2020;4:01.

20. Yoshida S, Kazuki I, Koji W. Prenatal and early-life antibiotic use and risk of childhood asthma: A retrospective cohort study. Pediatric Allergy and Immunology 2018; Volume 29 (5):490-9.

21. Obiakor C V, Hein M, Sarah L, Maria-Claire A, Anita L K. The association between early life antibiotic use and allergic disease in young children: recent insights and their implications. Expert Review of Clinical Immunology 2018; Volume 14 (10).

22. Deng Q, Chan Lu, Yuguo Li, Sundell J, Dan N. Exposure to outdoor air pollution during trimesters of pregnancy and childhood asthma, allergic rhinitis and eczema. Environmental Research 2016; Volume 150: 119-27.

23. Van der Aa LB, Heymans HS, Van Aalderen WM, J H Sillevis Smitt, J Knol, K Ben Amor, et al. Effect of a new synbiotic mixture on atopic dermatitis in infants: a randomized-controlled trial. Clinical \& Experimental Allergy 2011; 40, 795-804

24. Vandenplas, Y., Munasir, Z., Hegar, B., Kumarawati, D., Suryawan, A., Kadim, M., Djais, J. T., Basrowi, R. W., \& Krisnamurti, D. A perspective on partially hydrolyzed protein infant formula in nonexclusively breastfed infants. Korean journal of pediatrics 2019; 62(5), 149-154. https://doi.org/10.3345/kjp.2018.07276

25. Botteman MF, Munasir Z, Sulistomo AW, Horodniceanu EG, Bhanegaonkar AJ, Ji X, et al. Economic value of atopic dermatitis prevention via partially-hydrolyzed whey-based infant formula (PHF-W) use in high-risk, non-exclusively breastfed, Indonesian urban infants: results of a costeffectiveness model. World Nut J. 2019;2(2):43-55

26. Lamsal R, Zwicker JD. Economic evaluation of interventions for children with neurodevelopmental disorders: opportunities and challenges. Appl Health Econ Health Policy. 2017;15(6): 763-772

27. Bardosono S, Hildayani R, Chandra DN, Basrowi RW, Wibowo Y. The knowledge retention after continuing health education among midwives in Indonesia. Med $J$ Indones [Internet]. 2018Sep.9 [cited 2020Aug.7];27(2):128-33.

28. Ahmed M, Pai B, Reynolds T. Retention of knowledge of the Paediatric Life Support guidelines. J Coll Physicians Surg Pak. 2012;22(3):194-5. 